\title{
PERANCANGAN SISTEM INFORMASI PENERIMAAN SISWA BARU DI SMAN 1 KEBUN TEBU LAMPUNG BARAT MENGGUNAKAN PEMPROGRAMAN BORLAND DELPHI 7
}

\author{
DONI WINATA \\ 165100085, PBD 785567888 \\ Fakultas Komputer \\ doniwinata.student@umitra.ac.id
}

\begin{abstract}
Kemajuan teknologi informasi saat ini telah mengubah cara hidup masyarakat dalam menjalankan aktifitas sehari-hari. Keberadaan dan peranan teknologi informasi tanpa kita sadari telah memasuki era yang baru. Salah satu kebutuhan dari organisasi swasta maupun pemerintah dalam penyediaan sarana informasi adalah informasi yang berbasis teknologi komputerisasi, dimana sistem yang telah menggunakan komputerisasi memiliki tingkat kehandalan jauh lebih cepat serta lebih efisien dalam pengolahan data dibandingkan dengan system manual.
\end{abstract}

SMAN 1 KEBUN TEBU LAMPUNG BARAT adalah institusi dalam bidang pendidikan yang dalam pengolahan data penerimaan siswa barunya masih belum menggunakan suatu aplikasi khusus atau manual, sehingga mengakibatkan hasil kerja yang dicapai tidak maksimal dan memakan waktu yang lama. Oleh sebab itu dibuatlah perancangan sistem informasi penerimaan siswa baru menggunakan pemprograman Borland Delphi, dimana program ini diharapkan mampu menanggulangi masalah-masalah yang terjadi pada proses penerimaan siswa baru di SMAN 1 KEBUN TEBU LAMPUNG BARAT.

Kata Kunci : Perancangan Sistem Informasi Penerimaan Siswa Baru di SMAN 1 Kebun Tebu Menggunakan Pemprograman Borland Delphi 7. 


\section{A. INTRODUCTION}

$\begin{array}{lr}\text { PERANCANGAN } & \text { SISTEM } \\ \text { INFORMASI PENERIMAAN } \\ \text { SISWA BARU DI SMAN 1 KEBUN } \\ \text { TEBU LAMPUNG } \\ \text { MENGGUNAKAN } \\ \text { PEMPROGRAMAN } \\ \text { DELPHI } 7\end{array}$

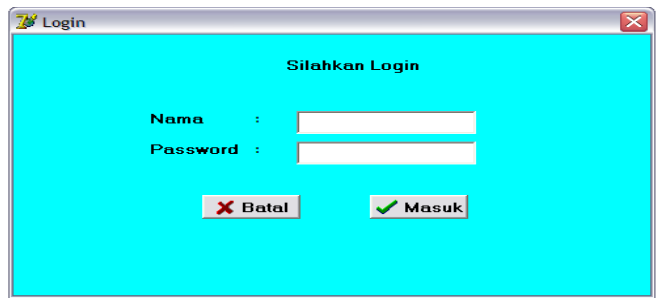

Kemajuan informasi diberbagai bidang telah dirasakan manfaatnya didalam kehidupan sehari-hari, baik bidang yang dikelola oleh instansi pemerintah maupun swasta. Kemajuan tersebut mempunyai peranan yang sangat penting dalam pembangunan nasional karena pembangunan yang dilakukan pada hakekatnya adalah merupakan suatu proses perubahan yang terus-menerus menuju pada perbaikan dan kemajuan, dimana saat ini telah menyentuh berbagai bidang. Kemajuan yang telah dicapai salah satunya yaitu bidang ilmu pengetahuan dan teknologi.

Perkembangan informasi saat ini memunculkan harapan yang dapat meningkatkan cara kerja yang efektif dan efisien. Dalam melaksanakan aktifitas pada instansi pemerintah maupun swasta dalam mengambil keputusan. Salah satu kebutuhan dari organisasi swasta maupun pemerintah dalam penyediaan sarana informasi adalah informasi yang berbasis teknologi. Dimana sistem yang telah menggunakan komputerisasi memiliki tingkat kehandalan yang jauh lebih cepat serta lebih efisien dalam pengolahan data bila dibandingkan dengan sistem manual, sehingga kebutuhan akan adanya komputerisasi dalam pengolahan data sangatlah dibutuhkan.

\section{SMAN 1 KEBUN TEBU LAMPUNG}

BARATmerupakan sekolah yang dalam perkembangan bertaraf nasional dalam pengolahan data penerimaan siswa barunya pada instansi pemerintah maupun swasta dalam mengambil keputusan. Salah satu kebutuhan dari organisasi swasta maupun pemerintah dalam penyediaan sarana informasi adalah informasi yang berbasis teknologi. Dimana sistem yang telah menggunakan komputerisasi memiliki tingkat kehandalan yang jauh lebih cepat serta lebih efisien dalam pengolahan data bila dibandingkan dengan system manual, sehingga kebutuhan akan adanya komputerisasi dalam pengolahan data sangatlah dibutuhkan. SMAN 1 KEBUN TEBU LAMPUNG BARAT merupakan sekolah yang dalamper kembangan bertaraf nasional dalam pengolahan data penerimaan siswa barunya pada SMAN 1 KEBUN TEBU LAMPUNG BARAT masih belum menggunakan aplikasi khusus dalam hal ini masih menggunakan aplikasi bawaan Microsoft (Word Dan Excel) bahkan kadang masih menggunakan pencatatan secara manual (menggunakan buku) yang mengakibatkan panitia penerimaan siswabarumelakukanpekerjaanyang berulang-ulang sehingga hasilkerja yangdicapaitidakefektifdan memakan waktu yang lama.Oleh sebab itu pengolahan data kesiswaan dan 
pembayaran secara komputerisasi sangatlah dibutuhkan agar dapat menghasilkan pekerjaan yang efektif dan efisien. Berdasarkan uraian diatas maka kami tertarik untuk membuat suatu penelitian ilmiah dengan judul perancangan system informasi penerimaan siswa baru pada SMAN 1 KEBUN TEBU LAMPUNG BARAT dengan menggunakan Pemrograman Delphi7.

\section{B. CONTENT}

\section{Sistem Informasi Sekolah}

"Sistem adalah kumpulan elemen berhubungan yang merupakan suatu kesatuan. Dari bahasa Latin dan orang Yunani, istilah "sistem" diartikan sebagai mengabungkan, untuk mendirikan, untuk menempatkan bersama. Suatu sistem biasanya terdiri komponen (atau elemen) yang dihubungkan bersama untuk memudahkan aliran informasi, materi atau energi"

"Informasi adalah data yang telah diproses menjadi bentuk yang memiliki arti bagi penerima dan dapat berupa fakta, suatu nilai yang bermanfaat. Jadi ada suatu proses transformasi data menjadi suatu informasi - input - proses - output."

"Sistem Informasi merupakan suatu kumpulan dari komponen komponen dalam perusahaan atau organisasi yang berhubungan dengan proses penciptaan dan pengaliran informasi."

"Administrasi sekolah adalah suatu proses yang terdiri dari usaha mengkreasi, memelihara, menstimulir, dan mempersatukan semua daya yang ada pada suatu lembaga Pendidikan agar tercapai tujuan yang telah ditentukan lebih dulu"

\section{Basis Data (Database)}

Basis data (database) adalah kumpulan dari berbagai data yang saling berhubungan satu dengan yang lainnya. Basis data tersimpan di perangkat keras, serta dimanipulasi dengan menggunakan perangkat lunak. Pendefinisian basis data meliputi spesifikasi dari tipe data, struktur dan batasan dari data ata informasi yang akan disimpan. Database merupakan salah satu komponen yang penting dalam sistem informasi, karena merupakan basis dalam menyediakan informasi pada para pengguna atau user.

Komponen-komponen dalam perancangan basis data secara konseptual antara lain:

1) Entitas terkadang disebut tipe entitas atau kelas entitas. Entitas menyatakan obyek atau kejadian.

2) Atribut adalah item data yang menjadi bagian dari entitas.

3) Hubungan adalah asosiasi atau kaitan antara dua entitas.

4) Domain adalah himpunan nilai yang berlaku bagi suatu atribut.

Perancangan basis data merupakan langkah untuk menentukan basis data yang diharapkan dapat mewakili seluruh kebutuhan pengguna, penentuan kunci merupakan hal yang paling esensial kunci tidak hanya sebagai metode untuk mengakses suatu basis tertentu. Tetapi sekaligus dapat menjadi pengenal unik (tidak ada yang sama/kembar) terhadap tabel. Namun perlu diketahui bahwa 
tidak semua kunci dapat menjadi pengenal yang unik karena terdapat beberapa istilah dalam pembagian kunci, menurut Kok Yung (2003: 6), pembagian kunci yaitu sebagai berikut:

1) Kunci kandidat (Candidate Key), yaitu satu atau lebih atribut yang mendefinisikan sebuah baris secara unik yang berfungsi sebagai calon dari kunci primer serta mempunyai nilai unik pada hampir setiap barisnya.

2) Kunci primer (Primary key), yaitu kunci kandidat yang sudah dipilih untuk mengidentifikasi baris secara unik yang berfungsi untuk mempermudah pengaturan dan perbaikan data yang umum digunakan adalah normalisasi. Dimana normalisasi adalah proses pegelompokan data elemen menjadi tabel-tabel yang menunjukkan entity dan relasinya.

3) Kunci alternatif (Alternate Key), yaitu kunci kandidat yang tidak dipilih untuk mengidentifikasi sebuah basis secara unik (Kunci Kandidat),

4) 4) Kunci tamu (Foreign Key), Yaitu kunci pada suatu tabel yang terhubung dengan kunci primer pada tabel lain.

\section{Normalisai}

Normalisasi merupakan suatu teknik dalam desain logika sebuah database, teknik pengelompokan atribut dari suatu relasi sehingga membentuk struktur relasi yang baik. Normalisasi dapat diartikan sebagai proses untuk mengubah suatu relasi yang memiliki masalah tertentu kedalam dua relasi atau lebih yang memiliki masalah tersebut. Masalah yang dimaksud disebut dengan anomali. Anomali adalah proses database yang memberikan efek samping yang tidak diharapkan, misalnya menyebabkan ketidak konsistenan data atau membuat suatu data menjadi hilang ketika data lain dihapus.

\section{Relasionship (Relasi)}

Istilah yang digunakan untuk menunjukkan relasi antar tabel yaitu kardinalitas/ derajat relasi. Kardinalitas menunjukkan jumlah maksimum entitas yang dapat berelasi dengan entitas lain. Contoh sejumlah kemungkinan banyaknya hubungan yang terjadi antar entitas (misalnya A dan B ) yaitu:

1) Relasi satu ke satu (one to one), yaitu setiap atribut pada himpunan A mempunyai hubungan dengan satu entitas pada himpunan B, dan himpunan B juga mempunyai satu hubungan entitas terhadap himpunan A.

2) Relasi satu ke banyak (one to many), yaitu hubungan yang terjadi apabila setiap record yang berada ditabel kiri mempunyai hubungan dengan beberapa record yang berada pada tabel sebelah kanan. Relasi banyak ke banyak (many to many) yang berarti setiap entitas pada himpunan A dapat berhubungan degan banyak entitas pada himpunan entitas $\mathrm{B}$, dan demikian juga sebaliknya dimana setiap entitas pada himpunan B 
dapat berhubungan dengan banyak entitas pada himpunan entitas A.

\section{Data Flow Diagram (DFD)}

DFD merupakan salah satu komponen dalam serangkaian pembuatan perancangan sebuah sistem komputerisasi. DFD menggambarkan aliran data dari sumber pemberi data (input) ke penerima data (output). Aliran data itu perlu diketahui agar sipembuat sistem tahu persis kapan sebuah data harus disimpan, kapan harus ditanggapi (proses), dan kapan harus didistribusikan ke bagian lain. DFD sering digunakan untuk menggambarkan suatu sistem yang telah ada atau sistem baru yang akan dikembangkan secara logika tanpa mempertimbangkan lingkungan fisik dimana data tersebut mengalir atau dimana data tersebut akan disimpan.

Aturan dalam menyusun sebuah DFD yaitu sebagai berikut:

1) antar entity yang satu dengan tidak boleh berhubung dengan anak panah secara langsung,

2) Entity tidak boleh langsung berhubungan dengan penyimpanan data(data storage),

3) satu aliran data tidak boleh merepresentasikan beberapa struktur data,

4) bentuk anak panah boleh bervariasi,

5) aliran data harus selalu diawali dan diakhiri dengan proses atau entity, dan

6) semua aliran data harus memiliki tanda arah.

\section{MY SQL}

MYSQ1 merupakan software sistem manajemen database (Database Management Sistem - DBMS) yang sangat terpopuler dikalangan pemprograman Web, terutama dilingkungan Linux dengan menggunaakan script PHP dan Perl. Software database ini kini telah tersedia juga pada platform sistem operasi Window (98/ME ataupun NT/2000?XP).

MYSQL digunakan karena kemudahannya untuk digunakan,cepat karena kerja query, dan mencukupi untuk kebutuhan database perusahaan-perusahaan skala menengah kecil. dan MYSQL merupakan database yang digunakan oleh situs-situs terkemuka di internet untuk menyimpan datanya.

\section{Borland Delpi}

Menurut Adi Wira Kusuma (2002:1), "Delphi adalah salah satu dari pemrograman secara visual, bahasa yang digunakan lebih mengarah kebahasa pascal". Menurut Inge Martina (2000: 13)" Borland Delphi merupakan program aplikasi database berbasis windows yang mempunyai kemampuan untuk menggunakan bahasa SQL (Struktur Query Languange)". Menurut Jack febrian (2004: 140), "Delphi adalah bahasa pemrograman under windows yang diproduksi oleh Borland, bahasa pemrograman ini merupakan pengembangan dari bahasa pemrograman pascal". Borland Delphi merupakan program aplikasi database yang dapat memberikan fasilitas pembuat aplikasi. Borland dephi merupakan program aplikasi database berbasis windows yang mempunyai 
kemampuan untuk menggunakan bahas SQL. Borland Delphi juga merupakan program aplikasi database yang berbasis object pascal dari Borland. Bahasa Delphi yang sebelumnya dikenal sebagai object pascal (pascal dengan ekstensi pemrograman berorientasi objek (PBO/OOP)) pada mulanya ditujukan hanya untuk Microsoft windows, namun saat ini telah mampu digunakan untuk pengambangan aplikasi untuk linux dan Microsoft. Umumnya Delphi lebih banyak digunakan untuk pengembangan aplikasi desktop dan enterprise database, tapi sebagai perangkat pengembangan yang bersifat generalpurpose ia juga mampu digunakan dalam berbagai jenis proyek pengembangan software.

\section{Tahap-Tahap Pengembangan Perangkat Lunak}

Pengembagan sistem yang digunakan adalah metode analisis dan desain sistem terstruktur (Structured system analysis and design). Adapun tahapan-tahapannya sebagai berikut:

1) Rekayasa Sistem (Engineering System), hal yang penting dilakukan ketuka perangkat lunak harus berkomunikasi dengan perangkat keras.

2) Analisis (Analysis), menganalisa dari data yang ada serta mengumpulkan kebutuhan-kebutuhan sistem yang akan dibangun.

3) Desain (Design), mendesain program yang akan dibuat secara keseluruhan.

4) Penulisan Program (coding), mengubah desain menjadi bentuk yang yang dimengerti oleh computer.

5) Pengujian (Testing), pengujian dapat di mulai dengan memfokuskan pada logika dari perangkat lunak.

6) Pemeliharaan (Maintenance), perangkat lunak yang sudah jadi mungkin ditemukan kesalahan atau ada hal yang baru ditambahkan, maka tahap pengembangan dilakukan di masa pemeliharaan.

\section{CONCLUSION}

Pada sistem ini, semua kegiatan yang berhubungan dengan pendaftaran siswa baru, pengolahan nilai, absensi, jadwal pelajaran, dan laporan keuangan dilakukan tidak lagi secara manual tetapi dengan menggunakan media berupa komputer. Sistem Penerimaan Siswa Baru yang berbasis komputer dapat menangani proses Penerimaan Siswa Baru dengan cepat dan akurat serta dapat di up-date dengan mudah.

Sistem ini memberikan beberapa keuntungan, diantaranya:

1) Siswa dapat mengakses data secara cepat,

2) data yang ada lebih up to date,

3) mendukung transparansi data,

4) penyimpanan data lebih efisien karena tidak perlu menuliskan nama. 


\section{DISCUSSION}

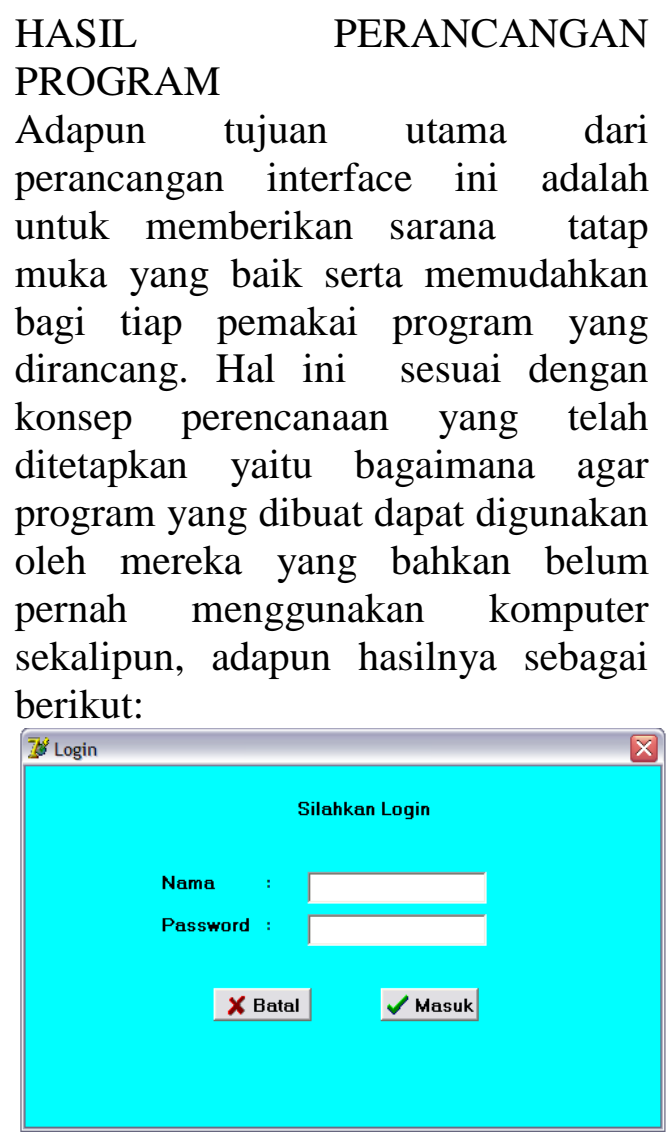

Form Login

\section{E. REFERENCE}

[1] O. M. Febriani and A. S. Putra, "Sistem Informasi Monitoring Inventori Barang Pada Balai Riset Standardisasi Industri Bandar Lampung," J. Inform., vol. 13, no. 1, pp. 90-98, 2014.

[2] A. S. Putra, "Paperplain: Execution Fundamental Create Application With Borland Delphi 7.0 University Of Mitra Indonesia," 2018.

[3] A. S. Putra, "2018 Artikel Struktur Data, Audit Dan Jaringan Komputer," 2018.

[4] A. S. Putra, "ALIAS MANAGER USED IN DATABASE DESKTOP STUDI CASE DB DEMOS."
A.
S.
Putra, "COMPREHENSIVE SET OF PROFESSIONAL FOR DISTRIBUTE COMPUTING."

[6] A. S. Putra, "DATA ORIENTED RECOGNITION IN BORLAND DELPHI 7.0."

[7] A. S. Putra, "EMBARCADERO DELPHI XE 2 IN GPUPOWERED FIREMONKEY APPLICATION."

[8] A. S. Putra, "HAK ATAS KEKAYAAN INTELEKTUAL DALAM DUNIA TEKNOLOGY BERBASIS REVOLUSI INDUSTRI 4.0."

[9] A. S. Putra, "IMPLEMENTASI PERATURAN PERUNDANGAN UU. NO 31 TAHUN 2000 TENTANG DESAIN INDUSTRI BERBASIS INFORMATION TECHNOLOGY."

[10] A. S. Putra, "IMPLEMENTATION OF 
PARADOX DBASE."

A. S. Putra,

"IMPLEMENTATION OF

TRADE SECRET CASE

STUDY SAMSUNG MOBILE PHONE."

[12] A. S. Putra, "IMPLEMENTATION

PATENT FOR APPLICATION WEB BASED CASE STUDI WWW. PUBLIKLAMPUNG. COM."

[13] A S. Putra, "IMPLEMENTATION SYSTEM FIRST TO INVENT IN DIGITALLY INDUSTRY."

[14] A. S. Putra, "MANUAL REPORT \& INTEGRATED DEVELOPMENT

ENVIRONMENT BORLAND DELPHI 7.0."

[15] A. S. Putra, "PATENT AS RELEVAN SUPPORT RESEARCH."

[16] A. S. Putra, "PATENT FOR RESEARCH STUDY CASE OF APPLE. Inc."

[17] A. S. Putra, "PATENT PROTECTION FOR APPLICATION INVENT."

[18] A. S. Putra, "QUICK REPORT IN PROPERTY PROGRAMMING."

[19] A. S. Putra, "REVIEW CIRCUIT LAYOUT COMPONENT

REQUIREMENT ON ASUS NOTEBOOK."

[20] A. S. Putra, "REVIEW TRADEMARK PATENT FOR INDUSTRIAL TECHNOLOGY BASED 4.0."

[21] A. S. Putra, "TOOLBAR COMPONENT PALLETTE IN OBJECT

ORIENTED
PROGRAMMING."

[22] A. S. Putra, "WORKING DIRECTORY SET FOR PARADOX 7."

[23] A. S. Putra, "ZQUERY CONNECTION

IMPLEMENTED

PROGRAMMING STUDI

CASE PT. BANK BCA Tbk."

[24] A. S. Putra, D. R. Aryanti, and I. Hartati, "Metode SAW (Simple Additive Weighting) sebagai Sistem Pendukung Keputusan Guru Berprestasi (Studi Kasus: SMK Global Surya)," in Prosiding Seminar Nasional Darmajaya, 2018, vol. 1, no. 1, pp. 85-97.

[25] A. S. Putra and O. M. Febriani, "Knowledge Management Online Application in PDAM Lampung Province," in Prosiding International conference on Information Technology and Business (ICITB), 2018, pp. 181-187.

[26] A. S. Putra, O. M. Febriani, and B. Bachry, "Implementasi Genetic Fuzzy System Untuk Mengidentifikasi Hasil Curian Kendaraan Bermotor Di Polda Lampung," SIMADA (Jurnal Sist. Inf. dan Manaj. Basis Data), vol. 1, no. 1, pp. 21-30, 2018.

[27] A. S. Putra, H. Sukri, and K. Zuhri, "Sistem Monitoring Realtime Jaringan Irigasi Desa (JIDES) Dengan Konsep Jaringan Sensor Nirkabel," IJEIS (Indonesian J. Electron. Instrum. Syst., vol. 8, no. 2, pp. 221-232.

[28] D. P. Sari, O. M. Febriani, and A. S. Putra, "Perancangan 
Sistem Informasi SDM

Berprestasi pada SD Global

Surya," in Prosiding Seminar

Nasional Darmajaya, 2018, vol.

1, no. 1, pp. 289-294. 